\title{
A Survey of Emergency Preparedness
}

\author{
Aaron Malveaux \\ Department of Computer Science \\ Howard University \\ Washington, DC USA
}

\author{
A. Nicki Washington, Ph.D. \\ Department of Computer Science \\ Howard University \\ Washington, DC USA
}

\begin{abstract}
Emergency preparedness is a discipline that harnesses technology, citizens, and government agencies to handle and potentially avoid natural disasters and emergencies. In this paper, a survey of the use of information technology, including social media, in emergency preparedness is presented. In addition, the current direction of research is identified, and future trends are forecasted that will lead to more effective and efficient methods of preparing for and responding to disasters.
\end{abstract}

Keywords-emergency preparedness; natural disasters; emergencies

\section{INTRODUCTION}

Emergency preparedness is a discipline that harnesses technology, citizens, and government agencies to handle and potentially avoid natural disasters and emergencies. Research in this field seeks ways to avert, guard against, and efficiently recover from emergency situations, especially those that pose a threat to the stability of society. In this paper a survey of the use of information technology in emergency preparedness is presented. The work also examines how social media can be leveraged to warn the public of emergencies and analyze how people respond to emergency situations. In addition, it analyzes systems used to increase awareness to the public and government agencies on the importance of supporting the technology to reduce the impact of disasters. Finally, the current direction of research is identified, and future trends that will lead to more effective and efficient methods of preparing for and responding to disasters are forecasted.

The remainder of this paper is organized as follows. Section II discusses current research in emergency preparedness. Section III presents taxonomy of the current research and identifies future trends. Finally, Section IV concludes.

\section{CURRENT TRENDS IN EMERGENCY PREPAREDNESS RESEARCH}

A review of the current literature on emergency preparedness identified several major trends in the research.

\section{A. Social Networking and the Citizen's Role in Emergency Management}

The use of the Internet as a resource during emergency situations has continued to augment over the years. The web has served as a vessel filled with vital information, and therefore, has introduced a novel and unique aspect to emergency preparedness research. Information from social networks can be used to monitor events in real time, as well as gather information after emergencies.
The level of social interaction via the web has increased exponentially. Social convergence has changed due to Web 2.0, allowing people to converge faster and from any location. Because of this, there has been an increase in public participation during disaster relief. The general archetypes of social convergence include helping, being anxious, returning, supporting, mourning, exploiting, and being curious [18]. Traces of each of the characteristics can be found when examining online behavior during disasters.

During disasters, people use online tools such as Twitter, Facebook, and Flickr. Online searches also help the anxious quickly determine who has been affected by the disaster and if they are safe. For example, online security cameras assisted families in California after wildfires, by informing them of the status of their property. After disasters, many people express support for relief efforts on social media sites and provide encouragement for those affected [12].

Apart from distributing information, researchers at the University of Colorado at Boulder examined social networking to understand the relationship between technology and social behavior during high profile events. Events such as the Republican National Convention, Democratic National Convention, Hurricane Gustav, and Hurricane Ike were reference points for data found on Twitter [11]. The study found that user-to-user communication decreases during large events. Instead of directing tweets at other users, people tend to direct their messages to the entire Twitter community. Also, the amount of tweets containing website addresses as references increases in order to provide more information than the 140 character tweet limit permits. The study concluded that the use of Twitter during mass incidents increased overall. In addition, Twitter can be exploited as a channel for the distribution of information. This was easy to identify when examining past events, but also shed light on limitations when examining real time information. An experiment conducted by the same group revealed that real-time, useful information can be extracted from Twitter in the event of a crisis, but the information is difficult to fully validate. The group suggested that in its current iteration, the information be accepted as a starting point for further investigation [9].

While Twitter serves as an effective outlet for text-based material, Flickr opens up a pathway for photographs that provide even more detail. The aforementioned study examined Flickr activity during major disasters to determine the volume of disaster-related posts and their relevance. They also interviewed top contributors, Flickr group administrators, and other interesting users, to determine what motivated users to share photographs. The research yielded that not only is their 
pertinent disaster information available on Flickr, but it is voluntarily generated and organized [17]. Disaster-related photographs, for events that have occurred since Flickr's launch in 2004, have their own page on the site. Not only did people post photographs of the aftermath, but they also utilized Flickr as a place to look for lost people and property damages. This large collection of data can aid in disaster preparation, response, and recovery.

Global Disaster Alert and Coordination System's (GDACS) research showed that, in many cases, social media was a more effective approach for information dissemination. This is because the information is able to reach more people in less time than traditional methods, such as television broadcasts, radio announcements, etc. Moreover, they discovered that social media users can report on events, sometimes with more accuracy than mass media outlets [5]. The GDACS plans to relay news gathered collectively from physical disaster parameters and social networks through a mobile application. The application will also allow users to upload photos with geolocation information, which can be analyzed and distributed according to regions.

The Social Emergency Management Information Systems (SocialEMIS) was developed in an effort to update emergency management plans. SocialEMIS focuses on collaboration during the contingency planning phase. Current emergency management systems focus mainly on collaboration during the response phase. Due to globalization, disasters can indirectly affect areas that are unconnected to the initial incident. Therefore, contingency planning must include all possible stakeholders. SocialEMIS uses collaborative preparedness and aims to involve all parties in the planning process, so that majority of the faults can be addressed before the response phase [2]. In future iterations, SocialEMIS will allow citizens to submit contingency plans associated with small-scale emergencies and use social networks to add information to databases.

\section{B. Human Response to Disaster}

During emergency events, people usually come together to help those in need. While these events can significantly affect victims, they also tend to be taxing on the first responders and public servants. A study observed the reaction of the New Orleans Police Department (NOPD) officers after their response to Hurricane Katrina [6]. Information was gathered on how first responders coped with disasters by which they were personally affected. Although many officers lost their homes or were in need of rescuing, their duty still called them to assist others. The study revealed that all officers experienced some form of emotional stress. However, not all handled the stress in the same way. Most officers relied on communication with other officers and family members, detachment, spirituality and religious beliefs, vices (e.g. cigarettes and alcohol), physical activity, and recollection of military training [6]. Communication between officers and their family proved best at helping officers cope. This suggested that the development of communication systems that allow first responders to communicate with their loved ones be developed and implemented. The study also

This work was supported by the DHS Scientific Leadership Award for Minority Serving Institutions Granting Bachelor's Degrees, award \#DHS-11ST-062-002. recommended that military survival training be included in the training of first responders.

Sometimes, even after training, the stress endured during a disaster can have strong mental effects on responder. In [7] the mental health of 207 subjects exposed to an airplane crash was monitored in stages. This study also included a control group of unexposed responder. The study found that the exposed responders were at an amplified risk (four times that of the control group) of developing acute stress disorder, posttraumatic stress disorder (PTSD), and depression. It suggested that they seek psychiatric care for emotional issues. The study showed that responders have a greater chance of developing acute stress disorder at least one week after the disaster, depression seven months after the disaster, and PTSD thirteen months after the disaster. The study also suggests that previous disaster experience puts responders at an even higher risk for developing PTSD. However, previous disaster experience is an intricate variable requiring more research [7]. The study implies that the results should be used to implement training on stress relief, as well as programs to help responders deal with stress following a disaster.

\section{Use of Information Technology During Emergencies}

The Committee on Research Priorities in Emergency Preparedness and Response for Public Health Systems found that current emergency response training systems must be expanded to address a wide variety of threats [1]. The committee identified the need for more interdisciplinary collaboration and inclusion of all levels of public health agencies, to create more effective emergency response plans and increase emergency preparedness.

Following the same trend, the Homeland Defense Center Network (HDCN) seeks to increase the presence of 3D simulation, modeling, and visualization in emergency planning, training, and decision support [3]. Many tools utilize modeling and simulation, but do not incorporate scalable virtual reality and simulation. Moreover, the ability to distribute data and findings throughout different simulation tools is missing. The HDCN is researching inexpensive and reusable simulation, modeling, and visualization and following emerging industry standards and guidelines. The HDCN has also created its own basic requirements for inexpensive, expandable, and sustainable 3D simulation, modeling, and visualization tools, with the intentions of making these advanced tools readily available to local, state, and federal emergency response teams [3]. When these tools were made available in other industries, training material retention increased by more than $25 \%$ and the viewing of training material increased by nearly $50 \%$. The HDCN is highly confident that these tools will allow emergency response teams to plan and train more effectively, while also providing responders with important information needed to safely and efficiently carry out their mission.

With the expansion of technology and its increase in affordability, more citizens now have access to powerful tools that can be used during disasters. It is noted that in disasters where traditional communication systems are unavailable, technology's role is reduced. However, the public remains an important source of information. Current federal programs do 
not utilize volunteered information and only allow volunteer participation in disaster response, leaving a huge void that the public usually fills [13].

Information technology can also be used in the disaster management phase. A National Research Council workshop sought to increase and optimize its use in disaster management [16]. The research focused on human characteristics that obstruct the application of information technology systems. The study found that improved wireless networking connectivity, the ability to fuse data from different sources, detection of change and balancing the role of humans and computers are all necessary to successfully use information technology during emergency events.

\section{Emergency Alert Systems}

Emergency alert systems, like amber alerts and weather alerts, serve an important role in emergency management. Unfortunately, these systems do not take advantage of the new media for information dissemination. Many alert systems still operate on television and radio networks and have not expanded to the Internet.

The Emergency Alert System (EAS) used in the United States does not have a strong presence on the Internet. Prompt notification of emergencies and guidance are essential elements to keeping the public safe. However, the current system leaves a significant population without information. A recent study asserted the characteristics of effective systems [4]. The characteristics found to be most operative are location-awareness, automated operation, non-intrusiveness, spontaneity, ubiquity, and support for second languages [4]. In order to be feasible, an Internet-based EAS requires the cooperation of the government, Internet service providers, and website operators to achieve the qualities that a viable EAS demands.

The GDACS also provided recommendations on an Internet based alert system [5]. It determined that, in many cases, social media, especially Twitter, was a more effective approach for circulating information and news. This was because the Internet reaches a broad audience in small time periods.

\section{E. Mobile Devices}

While the Internet previously only allowed widespread consumption of information distributed by a few groups, Web 2.0 allows information to flow freely to and from all users of the Internet [10]. Many web programs allow information to be collected by users, such as Wikipedia, Open Street Map, and Google Earth. However, there is a lack of methods that ensure quality and detect and remove errors. Mobile devices equipped with GPS hardware (included in a large portion of devices sold) can collect this information. With the rise of Web 2.0 and Global Positioning System (GPS) receivers, citizens can obtain information that is relevant to their location and surroundings. Without the conveniences that these systems offer, important information on events such as natural disasters or terrorist attacks would be lost to many people.

A study performed in part by the Institute for Environment and Sustainability examined how Volunteered Geographic Information (VGI) helps detect crisis events quickly and efficiently [8]. The study also explored how VGI can provide crisis management groups more accurate understanding of situations through photographs and social media updates. The group tested the validity of this claim by conducting two trials based on prior events. The first trial was conducted using a flood example and utilized only one social networking source. The second trial was conducted using a forest fire example and utilized two social networking sources. Once the information was stored and validated, the alerts were created and sent out to the organizations relevant to the emergency situation. The results of the trials showed that the system could provide high-level, useful information to emergency management organizations at affordable prices [8]. VGI can also be used to fill the shortage of geographical information worldwide [10].

Although cellular networks perform successfully most times, during emergencies, they are usually crippled and fail to function at full capacity. In an effort to remedy this weakness, a team of developers created the mobile ad hoc network MyMANET. MyMANET does not use typical communication technologies, but rather a lighter-weight infrastructure that is suitable for developing nations. MyMANET is a great contender for developing mobile ad hoc networks, because it is easy to use, efficient, and flexible. However, it is extremely vulnerable to security breaches. [14] As mentioned above, mobile devices enable citizens to easily share their locations and experiences. During disasters, this collective information can prove indispensable as a method to aid primary responders and concerned people.

\section{FUTURE TRENDS}

A review of the literature revealed a number of key and future research trends in emergency preparedness. Table 1 presents taxonomy of the current research in the area, including literature reviewed. This taxonomy was used to identify open areas of research and future trends.

Social media is still an open area of research in emergency preparedness. The majority of research is expected to move in the direction of incorporating social media into disaster response. The large increase of information on social media makes it a great resource for emergency management. People are sharing large parts of their lives on social media, and this typically increases during emergencies. Moreover, the information could be used during all phases of emergency management. Social media is also more accessible, as they provide platforms (APIs) that researchers or developers can use to extract and exploit the information. Researchers use social media data to track the roles of citizens during emergency events and map it to what is going on around them. 
TABLE I. TAXONOMY

\begin{tabular}{|l|l|l|l|l|l|}
\hline Paper & $\begin{array}{l}\text { Social } \\
\text { Networking }\end{array}$ & Human Response & $\begin{array}{l}\text { Information } \\
\text { Technology }\end{array}$ & Alert Systems & $\begin{array}{l}\text { Mobile } \\
\text { Devices }\end{array}$ \\
\hline $\mathbf{1}$ & & & X & & \\
\hline $\mathbf{2}$ & $\mathrm{X}$ & & & & \\
\hline $\mathbf{3}$ & & & $\mathrm{X}$ & & \\
\hline $\mathbf{4}$ & & & & $\mathrm{X}$ & \\
\hline $\mathbf{5}$ & $\mathrm{X}$ & & & $\mathrm{X}$ & \\
\hline $\mathbf{6}$ & & $\mathrm{X}$ & & & \\
\hline $\mathbf{7}$ & & $\mathrm{X}$ & & & \\
\hline $\mathbf{8}$ & $\mathrm{X}$ & & & & $\mathrm{X}$ \\
\hline $\mathbf{9}$ & $\mathrm{X}$ & & & & $\mathrm{X}$ \\
\hline $\mathbf{1 0}$ & $\mathrm{X}$ & & & & \\
\hline $\mathbf{1 1}$ & $\mathrm{X}$ & & & & \\
\hline $\mathbf{1 2}$ & $\mathrm{X}$ & & $\mathrm{X}$ & $\mathrm{X}$ \\
\hline $\mathbf{1 3}$ & & & & & $\mathrm{X}$ \\
\hline $\mathbf{1 4}$ & & & & & \\
\hline $\mathbf{1 5}$ & $\mathrm{X}$ & & $\mathrm{X}$ & & \\
\hline $\mathbf{1 6}$ & & & & & $\mathrm{X}$ \\
\hline $\mathbf{1 7}$ & $\mathrm{X}$ & & & & \\
\hline $\mathbf{1 8}$ & $\mathrm{X}$ & & & & \\
\hline
\end{tabular}

The observations are then used to determine whether social media can be used to detect emergency events.

Review of the literature also determined that online emergency alert systems have not been researched in depth. Traditional systems use radio and television to alert citizens of emergencies, but the users of those mediums are declining. More people are using Internet services that rival traditional radio and television broadcasts. The Internet is a popular platform and needs a sustainable and reliable alert system that can reach people and notify them of emergency situations. Twitter introduced an emergency alert system for organizations to leverage. However, it is strictly opt-in, so the scope of the system is limited. This is a step forward. However, it still falls short of replicating the success of television and radio alert systems.

\section{CONCLUSION}

In this study, the current literature in emergency response was reviewed to identify current and future trends. Research currently emphasizes the incorporation of social media into disaster response and the collaboration of governments and citizens. These two topics are very similar, because social media is the outlet that citizens use to aid in emergency management. However, it is an unofficial role. Dedicated mediums should be created for citizens to volunteer their time and information. Many of the studies examined in the survey show that there are users of social media who want to aid in the emergency management process. It is essential to offer support for information technology advances and utilize citizens during emergency management.

\section{ACKNOWLEDGMENT}

This work was supported by the DHS Scientific Leadership Award for Minority Serving Institutions Granting Bachelor's Degrees, under award \#DHS-11-ST-062-002.

\section{REFERENCES}

[1] Liu, S., Palen, L., Sutton, J., Hughes, A. and Vieweg, S. In Search of the Bigger Picture: The Emergent Role of On-Line Photo Sharing in Times of Disaster. In Proceedings of the 2008 ISCRAM Conference, 2008.
Retrieved from http://www.educause.edu/ero/article/online-socialmedia-crisis-events

[2] Hughes, Amanda L., Palen, Leysia, Sutton, Jeannette, Liu, Sophia B., Vieweg, Sarah. "Site-Seeing" in Disaster: An Examination of On-Line Social Convergence. Retrieved from https://www.cs.colorado.edu/ palen/Papers/iscram08/OnlineConvergenc eISCRAM08.pdf

[3] Hughes, Amanda L., Palen, Leysia. Twitter Adoption and Use in Mass Convergence and Emergency Events. In Proceedings of the 6th International ISCRAM Conference - Gothenburg, Sweden, 2009. Retrieved http://inderscience.metapress.com/content/h71150k3v8511021/

[4] De Longueville, B., Smith, R. S., \& Luraschi, G. OMG, from here, I can see the flames!: a use case of mining location based social networks to acquire spatio-temporal data on forest fires. In Proceedings of the 2009 International Workshop on Location Based Social Networks, 2009. Retrieved from http://dl.acm.org/citation.cfm?id=1629907

[5] Stollberg, B., de Groeve, T. The Use of Social Media within the Global Disaster Alert and Coordination System, 2012. Retrieved from http://www2012.org/proceedings/companion/p703.pdf

[6] Mejri, O. and Plebani, P. SocialEMIS: Improving Emergency Preparedness through Collaboration, 2012. Retrieved from http://delivery.acm.org/10.1145/2190000/2188182/p691mejri.pdf?ip $=138.238 .233 .9 \&$ acc $=$ ACTIVE\%20SERVICE\&CFID $=1423$ 95012\&CFTOKEN=72476836\&_acm_=1353069000_0f4ea6f0b3dce $6 \mathrm{c} 7 \mathrm{bf} 48 \mathrm{a} 22080 \mathrm{e} 370 \mathrm{cc}$

[7] Adams, T., Anderson, L., Turner, M., Armstrong, J. Coping through a Disaster: Lessons from Hurricane Katrina, 2011. Retrieved from http://pacercenter.org/media/18822/coping\%20through\%20adams\%20et \%20al.pdf

[8] Fullerton, S., Ursano, R., Wang, L. Acute Stress Disorder, Posttraumatic Stress Disorder, and depression in Disaster and or Rescue Workers, 2004. Retrieved from http://ajp.psychiatryonline.org/article.aspx?articleID $=176964$

[9] Altevogt, B. M., Pope, A. M., Hill, M. N., and Shine, K. I. Research priorities in emergency preparedness and response for public health systems: A letter report, 2008. Retrieved from http://www.nap.edu/catalog/12136.html

[10] Emergency Preparedness, Response and Mitigation, 2003. Retrieved from http://delivery.acm.org/10.1145/1040000/1030959/p1061corley.pdf?ip=138.238.233.9\&acc $=$ ACTIVE\%20SERVICE $\&$ CFID $=153$ $951563 \&$ CFTOKEN $=98287454 \& \_$acm _ $=1354893839 \_$ffe $66 \mathrm{c} 22 \mathrm{a} 670$ 529b7e5fc1dd09d19660

[11] Palen, Leysia, Liu, Sophia B. Citizen communications in crisis: anticipating a future of ICT-supported public participation. In Proceedings of the SIGCHI Conference on Human Factors in 
Computing Systems, 2007. Retrieved from http://dl.acm.org/citation.cfm?id=1240736

[12] National Research Council, Committee on Using Information Technology to Enhance Disaster Management. Improving disaster management: The role of it in mitigation, preparedness, response, and recovery, 2007. Retrieved from National Academies Press website: http://www.nap.edu/catalog.php?record_id=11824

[13] Verma, P., Verma, D. Internet Emergency Alert System, 2005. Retrieved from

http://domino.watson.ibm.com/library/cyberdig.nsf/papers/2DF643D577 E6C48985256FF0005191CA/\$File/rc23594.pdf
[14] Goodchild, Michael F. Citizens as Voluntary Sensors: Spatial Data Infrastructure in the World of Web 2.0. In International Journal of Spatial Data Infrastructures Research, 2007, Vol. 2, 24-32, 2007. Retrieved http://ijsdir.jrc.ec.europa.eu/index.php/ijsdir/article/view/28

[15] Schade, S., Díaz L., Ostermann, F., Spinsanti L., Luraschi, G., Cox, S., Nuñez, M., DeLongueville, B. Citizen-based sensing of crisis events: sensor web enablement for volunteered geographic

[16] Paranjpe, A., and Vempala, S. Mymanet: A customizable mobile ad hoc network, 2009. Retrieved rom http://www.dritte.org/nsdr09/files/nsdr09_camera/s4p2_paranjpe09nsdr. pdf 